\title{
Robot-assisted laparoscopic heller myotomy using the DaVinci Xi
}

\author{
David S. Demos, William B. Tisol
}

Aurora St. Luke's Medical Center, Milwaukee, Wisconsin, USA

Contributions: (I) Conception and design: Both authors; (II) Administrative support: Both authors; (III) Provision of study materials or patients: Both authors; (IV) Collection and assembly of data: Both authors; (V) Data analysis and interpretation: Both authors; (VI) Manuscript writing: Both authors; (VII) Final approval of manuscript: Both authors.

Correspondence to: David S. Demos, MD. Aurora St. Luke's Medical Center, 2901 W. Kinnickinnic River Pkwy, Professional Office Bldg 1, Suite 507, Milwaukee, Wisconsin, USA. Email: ddemosmd@outlook.com.

\begin{abstract}
Definitive therapy for achalasia remains an esophageal myotomy across the gastroesophageal junction (GEJ). Approaches to myotomy include transthoracic and transabdominal techniques, both open and minimally invasive. Advantages of a transabdominal approach include full access to the stomach below the GEJ for complete myotomy, the angle of approach to the myotomy, and fundoplication. The use of the Da Vinci Xi surgical robot (Intuitive Surgical, Sunnyvale, CA, USA) adds some distinct advantages to the laparoscopic approach. These include: (I) a steady camera with high-definition, three-dimensional view of the circumferential muscle fibers, (II) tremor reduction through the robotic console, (III) wristed instruments providing flexibility in angle of approach and dexterity, and (IV) bi-polar energy use for more delicate, precise fiber division without excessive thermal spread. The advantage of bi-polar energy delivery over monopolar cautery cannot be overstated. We describe our approach to DaVinci Xi Robot-assisted laparoscopic modified heller myotomy with anterior partial fundoplication.
\end{abstract}

Keywords: Achalasia; robotic laparoscopic heller esophageal myotomy; DaVinci Xi

Received: 06 December 2019; Accepted: 30 January 2020; Published: 20 April 2021.

doi: 10.21037 /jovs.2020.02.03

View this article at: http://dx.doi.org/10.21037/jovs.2020.02.03

\section{Introduction}

Esophageal myotomy was first performed in the early 1900's by German surgeon E. Heller, dividing the circumferential muscle fibers both anteriorly and posteriorly. This was later modified to a single myotomy. Approaches have included transthoracic and transabdominal techniques, both open and minimally invasive. Advantages of a transabdominal approach include full access to the stomach below the gastroesophageal junction (GEJ) for complete myotomy, the angle of approach to the myotomy, and fundoplication. While the inclusion of fundoplication after myotomy is somewhat controversial due to the balance between esophageal emptying and reflux, the incidence of post-myotomy reflux is not trivial. In a recent randomized trial by Ponds et al., $41 \%$ of patients experience clinically significant reflux esophagitis following per oral endoscopic myotomy (POEM) (1). The use of the Da Vinci $\mathrm{Xi}$ surgical robot (Intuitive Surgical, Sunnyvale, CA, USA) adds some distinct advantages to the laparoscopic approach. These include: (I) a steady camera with high-definition, three-dimensional view of the circumferential muscle fibers, (II) tremor reduction through the robotic console, (III) wristed instruments providing flexibility in angle of approach and dexterity, and (IV) bi-polar energy use for more delicate, precise fiber division without excessive thermal spread. The advantage of bi-polar energy delivery over monopolar cautery cannot be overstated. These advantages may translate to improved outcomes (2-4). We describe our approach to DaVinci Xi Robot-assisted laparoscopic heller myotomy with anterior partial fundoplication.

\section{Preoperative planning}

Standard preoperative evaluation for achalasia is completed including barium esophagram, esophageal manometry, computed tomography of the chest, and upper endoscopy. 
Table 1 Port placement strategy

\begin{tabular}{lclll}
\hline Port & Size $(\mathrm{mm})$ & Location & Hand & Instrument \\
\hline Arm 1 & 8 & Right subcostal & Left & Small grasping retractor \\
Arm 2 & 8 & Right side between Arms 1 and 3 & Left & Cadiere \\
Arm 3 & 8 & Two fingerbreadths superior and left of umbilicus & Camera \\
Arm 4 & 8 & Left subcostal & Right & Long bipolar forceps \\
Assistant port & 11 & Left side between Arms 3 and 4 & Assistant & Suction or laparoscopic grasper \\
\hline
\end{tabular}

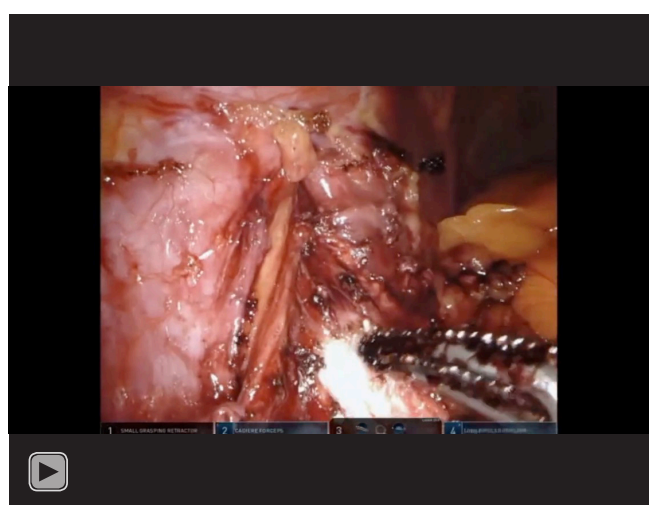

Video 1 Conduct of robot-assisted laparoscopic heller myotomy using the DaVinci Xi.

\section{Anesthesia and positioning}

General anesthesia is induced with single-lumen orotracheal intubation. Only peripheral intravenous access is needed. Central access, if necessary, for any reason, can be established in the internal jugular vein or either groin. Arterial line placement is not routinely necessary. Upper endoscopy is performed to confirm the diagnosis. The endoscope is left in the esophageal lumen at mid-esophagus for later use, with the light turned off. The patient is placed supine with both arms tucked.

\section{Port placement and docking}

Port placement for this procedure is generally acceptable for all foregut operations. It utilizes all $8 \mathrm{~mm}$ ports, essentially in the same transverse plane. We prefer blunt needle abdominal insufflation just below the left costal margin. A camera port is placed two fingerbreadths superior and left of the umbilicus. This can be adjusted for patients with very long torsos. Next, the right subcostal retraction arm port is placed in the same transverse plane as far laterally as is safe. An additional working arm port is placed splitting the difference between the first two. The camera is then placed in one of the right-sided ports to allow clear visualization of the left side. A left subcostal port is placed as far laterally as is safe, again in the same transverse plane as the prior three ports. An $11 \mathrm{~mm}$ assistant port is then placed, again splitting the difference between the camera and left subcostal port. The patient is placed in slight reverse Trendelenburg and the robot is then brought into place for docking. The instruments are inserted under direct vision (Table 1).

\section{Technique}

The following technique can be viewed in its entirety in Video 1. The small grasping retractor in arm 1 is placed under the liver and the left lobe of the liver is retracted anteriorly with the jaws open to allow for broader exposure of the hiatus. The cadiere is then used in arm 2 along with the long bipolar in arm 4. First the gastrohepatic ligament is opened and the right diaphragmatic crus is exposed. The hiatus is then entered anterior to the esophagus. The anterior surface of the esophagus is then followed into the mediastinum about $10 \mathrm{~cm}$ to ensure the ability to perform an adequate myotomy. The GEJ fat pad is then elevated starting from the cardia of the stomach. This is facilitated by having the bedside assistant retract the fundus, first to the left to expose the gastric portion of the fat pad. Once the gastric portion of the fat pad is elevated off the stomach and the angle of His is identified, the bedside assistant retracts the fundus more toward the right. The fat pad can then be elevated off the GEJ from left to right, staying on the esophageal wall to avoid injury to the anterior vagus nerve and mobilize it to facilitate the myotomy. Once the vagus nerve is well mobilized off of the surface of the GEJ, the myotomy may commence.

The GEJ is precisely identified, and the myotomy is 
begun where the longitudinal esophageal muscle fibers are clearly visible. Using the long bipolar forceps, a careful spreading technique is performed to separate the longitudinal fibers and expose the circumferential fibers. Careful spreading is again used to get underneath the circumferential fibers and onto the esophageal mucosa. The circumferential fibers are then carefully divided at this level. The cadiere forceps are used to grasp the left side of the myotomy and carefully slightly elevate and stabilize the leading edge. The bipolar forceps are used to carefully spread between the circumferential fibers and the mucosa, separating the two. This plane is relatively avascular, and any substantial bleeding during this dissection suggests the dissection has proceeded too deep toward the mucosa. The separated fibers are then divided with the bipolar forceps. This technique is carried proximally for $6-8 \mathrm{~cm}$ above the GEJ. It is important to occasionally assess the direction of the myotomy, as deviation obliquely around the left side of the esophagus can occur, especially if a hiatal hernia is present and repaired at the time of surgery. Measurement can be made easy by marking the long laparoscopic suction device with a marker every $1 \mathrm{~cm}$ from the tip.

Next, the gastric myotomy is performed. The bedside assistant retracts the fundus to screen right. The GEJ is again identified, and a point $2-3 \mathrm{~cm}$ distal to it on the stomach is identified for continuation of the myotomy. The myotomy is then continued from where it was started distally onto the stomach to the previously identified point. The muscle fibers are divided until the submucosal plexus is encountered. This layer bleeds more readily than at the level of the esophagus. Any mucosal defects that are created can be repaired with Vicryl suture. The gastroscope is again turned on and used to confirm that an adequate myotomy has been performed by easy passage into the stomach.

Finally, a fundoplication is performed. We prefer an anterior partial fundoplication. Suturing is performed with 2-0 Ethibond and all sutures are secured with the long Cor-Knot device by the bedside assistant. The angle of His is identified. A stitch is passed through the stomach and the GEJ at this level lateral to the myotomy to recreate and secure the angle of His. The next stitch is passed $1 \mathrm{~cm}$ cephalad to this, first through the stomach, next through the left crus, and finally through the GEJ. The fundus is then retracted across to the right side of the GEJ to identify an appropriate position for the next suture and to assess for any tension on the short gastric arteries and spleen. It is rarely necessary to divide the short gastric arteries because of this. A stitch is then placed through the fundus, the right side of the GEJ, and then the right diaphragmatic crus. Two additional sutures are placed in this manner $1 \mathrm{~cm}$ apart to complete the fundoplication. Finally, we place one suture anteriorly from the fundus to the anterior hiatus to prevent herniation.

\section{Postoperative care}

Patients are admitted to the stepdown floor postoperatively. They are maintained on IV fluids. A clear liquid diet is initiated in the evening on the day of surgery. Full liquids are initiated in the morning on postoperative day 1 . The patients are advanced to a soft diet prior to discharge, either on postoperative days 1 or 2 as clinically appropriate. A contrast esophagram is not routinely obtained, but may performed if clinically appropriate or there are any concerns about the conduct of the operation.

\section{Conclusions}

We describe our technique in performing a robot-assisted laparoscopic modified heller myotomy using the DaVinci Xi robot platform. The main advantages of the robot-assisted approach are the magnified, stereotactic view provided by the camera, the use of bipolar energy, and the increased stability and dexterity provided by the instruments.

\section{Acknowledgments}

Funding: None.

\section{Footnote}

Provenance and Peer Review: This article was commissioned by the Guest Editor (Douglas Z Liou) for the series "Advancement in Treatment for Esophageal Diseases". This article has undergone external peer review.

Conflicts of Interest: Both authors have completed the ICMJE uniform disclosure form (available at https://jovs.amegroups. com/article/view/10.21037/jovs.2020.02.03/coif). The series "Advancement in Treatment for Esophageal Diseases" was commissioned by the editorial office without any sponsorship or funding. DSD is a robotic thoracic surgery proctor for Intuitive Surgical, Inc. WBT is a robotic thoracic surgery case observation site administrator and course instructor for Intuitive Surgical, Inc. 
Ethical Statement: The authors are accountable for all aspects of the work in ensuring that questions related to the accuracy or integrity of any part of the work are appropriately investigated and resolved. All procedures performed in this study were in accordance with the Helsinki Declaration (as revised in 2013). The manuscript is waived from patient informed consent according to the ethics committee or institutional review board.

Open Access Statement: This is an Open Access article distributed in accordance with the Creative Commons Attribution-NonCommercial-NoDerivs 4.0 International License (CC BY-NC-ND 4.0), which permits the noncommercial replication and distribution of the article with the strict proviso that no changes or edits are made and the original work is properly cited (including links to both the formal publication through the relevant DOI and the license). See: https://creativecommons.org/licenses/by-nc-nd/4.0/.

doi: 10.21037 /jovs.2020.02.03

Cite this article as: Demos DS, Tisol WB. Robot-assisted laparoscopic heller myotomy using the DaVinci Xi. J Vis Surg 2021;7:12.

\section{References}

1. Ponds FA, Fockens P, Lei A, et al. Effect of Peroral Endoscopic Myotomy vs Pneumatic Dilation on Symptom Severity and Treatment Outcomes Among TreatmentNaive Patients With Achalasia: A Randomized Clinical Trial. JAMA 2019;322:134-44.

2. Ali AB, Khan NA, Nguyen DT, et al. Robotic and per-oral endoscopic myotomy have fewer technical complications compared to laparoscopic Heller myotomy. Surg Endosc 2020;34:3191-6.

3. Milone M, Manigrasso M, Vertaldi S, et al. Robotic versus laparoscopic approach to treat symptomatic achalasia: systematic review with meta-analysis. Dis Esophagus 2019;32:1-8.

4. Kim SS, Guillen-Rodriguez J, Little AG. Optimal surgical intervention for achalasia: laparoscopic or robotic approach. J Robot Surg 2019;13:397-400. 